\title{
A SINCERIDADE NA ÉTICA DISCURSIVA DE HABERMAS E A TRANSPARÊNCIA NO CONTROLE MIDIÁTICO NO BRASIL
}

\author{
Jenifer Bueno Diniz ${ }^{1}$ \\ José Marcos Miné Vanzella²
}

RESUMO: O presente artigo, com metodologia filosófica, bibliográfica e documental, tem por objetivo investigar a questão da autenticidade dos meios de comunicação de massa no Brasil. Apresenta pesquisa realizada pela organização Repórteres Sem Fronteiras e pelo Coletivo Intervozes e sua relação com os fundamentos da democracia a partir do pensamento de Habermas. Analisa a transparência na identificação dos proprietários dos maiores grupos midiáticos em operação no Brasil e o atendimento às regras da ética do discurso, requisitos para uma comunicação democrática válida. Conclui que não há transparência na identificação dos proprietários nem atendimento ao requisito da sinceridade.

PALAVRAS-CHAVE: Democracia, Ética do discurso, Controle da mídia, Sinceridade no discurso, Transparência, Jürgen Habermas

\section{SINCERITY IN HABERMAS'S DISCURSIVE ETHICS AND THE TRANSPARENCY IN THE MEDIA CONTROL IN BRAZIL}

ABSTRACT: This article, with philosophical, bibliographical and documentary methodology, aims to investigate the question of authenticity of mass media in Brazil. Presents research carried out by the organizations Reporters without Borders and Coletivo Intervozes and its relationship to the foundations of democracy from the thought of Habermas. Analyzes the transparency in the identification of the individual owners of the biggest groups of media communication in Brazil and the compliance with the rules of discourse ethics, requirements for a valid democratic communication. Concludes that there is no transparency in identifying the owners or meeting the requirement of sincerity.

KEYWORDS: Democracy, Discourse ethics, Media control, Sincerity in the discourse, Transparency, Jürgen Habermas

\footnotetext{
${ }^{1}$ Pós-graduada lato sensu em Direito Constitucional pela Universidade Anhanguera - UNIDERP. Mestranda em Direito pelo UNISAL - Centro Universitário Salesiano - Lorena. E-mail: jeniferbd@hotmail.com.

2 Doutor em Filosofia pela Universidade Gama Filho (Rio de Janeiro). Professor e Pesquisador no Programa de Mestrado em Direito do Centro Unisal - U.E. Lorena (SP). Professor da Faculdade Dehoniana - FADE Taubaté. E-mail: enimine@gmail.com.
} 


\section{INTRODUÇÃO}

Uma sociedade democrática pressupõe a existência de mecanismos de debates de ideias e conceitos, teorias e programas políticos, a fim de que se obtenha o consenso mediante a possibilidade de participação de todos e a possibilidade de análise de todas as perspectivas, e não somente das teorias e programas de governo tradicionais.

O presente artigo investiga com metodologia filosófica, bibliográfica e documental a questão da avaliação da autenticidade dos meios de comunicação de massa e sua relação com os fundamentos da democracia a partir do pensamento de Habermas. Tal pesquisa, portanto, encontra abrigo na temática do Grupo de Trabalho “Teorias da Democracia e Direitos Políticos”, vez que analisa formas de participação política e debate de ideias em uma arena de comunicação informal - neste trabalho representada pelos meios de comunicação em massa em que se manifesta o pluralismo político, e cuja regularidade exige-se como base para um processo democrático válido.

Partindo-se desse pressuposto, esse trabalho analisa a transparência no controle midiático no Brasil, ou seja, na identificação dos indivíduos proprietários das empresas de comunicação com maior alcance no país, e o atendimento ou não ao requisito da sinceridade na ética discursiva de Habermas, objetivando constatar a qualidade da comunicação advinda dos maiores grupos de mídia do país. Questiona como a transparência da informação sobre os donos e efetivos detentores do poder decisório nos meios de comunicação de massa no Brasil compromete sua autenticidade, e condições necessárias da ética do discurso, pondo em risco a livre formação da opinião e da vontade, um dos grandes fundamentos da democracia.

Tem por objetivo contribuir para o esclarecimento da situação da transparência na relação mídia e cidadão no Brasil, que é condição de uma esfera pública livre promotora da democracia. Para tanto abordam-se os seguintes temas: Habermas e requisitos éticos da teoria do discurso; o espaço informal da formação da opinião pública e o controle da mídia no Brasil: pesquisa sobre a transparência dos proprietários da mídia; e, por fim, a sinceridade na ética discursiva e a transparência no controle midiático no Brasil.

\section{Habermas e a Teoria do Discurso: requisitos da ética discursiva}

Jürgen Habermas é um filósofo e sociólogo alemão representante da segunda geração da Escola de Frankfurt. Habermas foi assistente do filósofo e sociólogo Theodor W. Adorno 
durante cinco anos, até 1959. Passou a lecionar filosofia aos 31 anos e, em 1961, publicou a obra "Entre a Filosofia e a Ciência - O Marxismo como Crítica”. Em 1981, Habermas publicou a "Teoria da Ação Comunicativa”, considerada uma de suas obras mais importantes. Posteriormente, continuou a desenvolver sua teoria do discurso na obra "Consciência Moral e Agir Comunicativo”, de 1983.

Aposentado em 1994, Habermas permaneceu realizando um trabalho profícuo com a publicação de muitas obras e a realização de palestras. "Segundo Dupeyrik, o espaço público, o patriotismo constitucional, a razão comunicativa, a ética da discussão, o consenso, a democracia deliberativa, o procedimentalismo e a sociedade pós-secular são conceitos destacados de sua filosofia” (MARQUES, 2015, on-line).

O próprio Habermas relata as raízes biográficas de sua preocupação com a comunicação, recordando de seus problemas de comunicação por conta de ter nascido sem o palato e ter lábios leporinos numa Alemanha então nazista. Trata-se de fala proferida durante a entrega do prêmio Kyoto por contribuições para o desenvolvimento da humanidade, em junho de 2004, a qual integra uma parte do primeiro capítulo de seu livro "Entre Naturalismo e Religião” (2007). Nesse texto ele também afirma:

\begin{abstract}
A esfera pública, entendida como espaço do trato comunicativo e racional entre as pessoas, é o tema que me persegue a vida toda. De fato, a tríade constituída pela esfera pública, pelo discurso e pela razão dominou minha vida política e meu trabalho científico. Toda a obsessão, no entanto, possui raízes na história de uma vida. (2007, p.19)
\end{abstract}

Atentando-se aos problemas da comunicação e partindo da ideia de que todo discurso nasce com o objetivo de que seja compreendido, Habermas passa a desenvolver a sua "Ética do Discurso” com seu parceiro Karl Otto Apel, cujos princípios Marques sintetiza nos seguintes termos:

A convivência humana pacífica não pode prescindir de princípios morais mínimos na
relação interpessoal. Entender que o outro existe e possui os mesmos direitos, saber
que a comunicação não pode ser forçada, isto é, o destinatário deve livremente receber
a mensagem sem qualquer forma de coação, ter livre disposição para solucionar as
questões e permitir um discurso igualitário na fundamentação das normas legais ou
decisões judiciais faz parte da ética do discurso apresentada por Habermas.
(MARQUES, 2015, on-line)

É importante entender que para os autores o que está em jogo é a convivência pacífica, a qual exige a observância de princípios. Do contrário os conflitos entre as partes na 
comunicação acontecem. A “ética do discurso” coloca-se como uma alternativa pragmática à descrição que Thomas Hobbes faz das relações humanas e de seu estado de miséria condição de guerra que é resultado de suas paixões naturais (Hobbes, 1988, p. 103). Por esse motivo a ética do discurso recupera a dimensão racional e interpessoal dos seres humanos. Nos termos de Marques:

A ética do discurso busca dar à ética um fundamento racional através da idéia de que a reflexão sobre os pressupostos da comunicação interpessoal permite identificar os princípios morais realmente irrenunciáveis que devem ser a base de toda convivência humana: o reconhecimento do outro, a não coação da comunicação e a disposição para a solução de problemas e a fundamentação de normas através do discurso livre e igual. (2015, on-line).

É fundamental compreender a explicitação da contradição performativa de Hobbes que Habermas manifesta no capítulo III da sua obra “Direito e democracia” (2010, vol. I). O sistema do egoísmo ordenado é em si mesmo performativamente autocontraditório, não pode fundar um contrato social. Só então pode-se entender adequadamente a legitimação do direito pela via do discurso e a distinção dos respectivos jogos de linguagem da ética do discurso, mais genérica e sua especificação para a moral e para o direito. Assim se entende porque a Ética do discurso é base para toda a convivência humana que reconhece o outro e fundamenta normas num discurso livre e igual. Neste sentido pode-se dizer que:

[...] Habermas utiliza o conceito do agir comunicativo como base para sua teoria do consenso, pois onde não existe a possibilidade de uma comunicação livre, em que todos tenham condições para que possam se manifestar sempre que assim o desejarem, não será possível a busca do consenso para a solução dos conflitos e discussões de qualquer área do saber humano. (MARQUES, 2015, on-line).

O estudo das regras comunicativas e da cunhada Teoria do Discurso de Habermas relaciona-se diretamente com as regras do chamado "jogo democrático": uma democracia fundada apenas em regras formais de participação no processo político - aqui considerado formalmente apenas como um conjunto de regras para o exercício do poder em uma organização político-administrativa em forma de Estado - não seria justificável aos olhos de todos os participantes do processo democrático (HABERMAS, 2010, vol. II).

Habermas, em suas obras, parte do pressuposto de uma divisão entre Sistema (Economia e Estado) e Mundo da Vida (Esfera Privada e Esfera Pública). Assim, no mundo da vida seriam formadas as discussões informais que influenciariam o sistema (e, naturalmente, 
seriam influenciadas por ele), o que denota a importância que o autor dá ao estudo desses processos comunicativos informais, já que são fundamentais no exercício da cidadania e no desenvolvimento de processos democráticos.

\begin{abstract}
Habermas não é conclusivo quanto à cidadania, não dá um significado ou conceito fechado, mas trabalha com ela em toda sua obra. A cidadania está presente no desenvolver da teoria da ação comunicativa, na mudança estrutural da esfera pública e naquilo que ela se transformou, chegando aos dias de hoje, e principalmente em sua ideia de democracia deliberativa. Mais do que uma ideia de cidadania ativa, que segundo Soares "Institui o cidadão como portador de direitos e deveres, mas essencialmente participante da esfera pública e criador de novos direitos para abrir espaços de participação", (2004, p.46) Habermas propõe uma reformulação estrutural do modelo político no qual o indivíduo comunicativo passa a ser parte constitutiva do poder público, fazendo parte de sua estrutura através do poder comunicativo, da sua capacidade de pensar e discutir problemas publicamente. (RIBEIRO, TEMER e TUZZO, 2013, p. 198).
\end{abstract}

Habermas, portanto, desenvolve sua teoria do discurso com base nas teorias da comunicação, identificando e estabelecendo requisitos e condições formais para a concretização de uma comunicação efetiva no espaço público informal, no qual são formadas e debatidas as opiniões que afetarão e determinação o processo político.

Habermas afirma que toda fala traz em si quatro pretensões: inteligibilidade, para que o ouvinte possa entender; verdade, que o conteúdo comunicado seja verdadeiro; sinceridade, manifestação sincera das intenções do falante; e correção, ou seja, escolher a manifestação correta, conforme as normas da sociedade. Referidas pretensões são apresentadas por ele como requisitos para uma ética discursiva (NOGUEIRA, 2006).

Em análise de sua Teoria do Discurso observa-se que os referidos requisitos são apresentados como critérios formais que viabilizam a realização do processo democrático, visto que o seu preenchimento permite o desenvolvimento de um espaço adequado de comunicação e debate, e também ocupam um papel, portanto, de um mecanismo de realização do sistema de direitos de um determinado Estado.

A Teoria do discurso de Habermas é construída como uma "teoria social baseada na linguagem que funciona também como uma possibilidade, ou utopia, de autodeterminação da sociedade de forma a validar a cidadania [...]” (RIBEIRO, TEMER e TUZZO, 2013, p. 191).

Contudo, Habermas não se restringe a uma situação de idealização das comunicações humanas:

Apesar dos numerosos mal-entendidos, recriminações e criticismos que acompanham Habermas também, na sua obra, se pode vislumbrar uma diferença em relação a uma 
concepção forte de universalismo metafísico subscrita por Apel em torno da sua comunidade ideal de fala. Habermas afirma que o seu discurso ético é aberto ao pluralismo de valores, requerendo acordo apenas acerca dos princípios que informam o próprio discurso. Ou seja, como não é mais possível sob o ponto de vista teórico defender a validade das razões últimas, são as condições formais de justificação que adquirem elas mesmas um poder de legitimação. (CORREIA, 2005, p. 46)

Assim, pode-se dizer que "o novo paradigma da racionalidade não é substantivo, mas discursivo: tematiza não o conteúdo mas a forma dos procedimentos argumentativos” (CORREIA, 2005, p. 41). Os requisitos apresentados pelo autor constituem, portanto, critérios objetivos por meio dos quais, buscando-se esse ideal de comunicação, pode-se avaliar, justificar e legitimar o processo de discussão e formação da opinião necessário ao processo democrático.

\title{
2 O espaço informal de formação da opinião e o controle da mídia no Brasil: pesquisa sobre a transparência dos proprietários da mídia
}

Como já mencionado, Habermas fala em suas obras sobre a esfera pública constituída por espaços em que ocorre a formação da opinião e da vontade. Uma dessas possibilidades de discussão, debate e formação informal da opinião se dá através da mídia nacional, tais como nos veículos de televisão, rádio, jornais e sítios eletrônicos (internet), além de outros meios de comunicação informal, a maioria também pela internet.

A mídia não somente torna públicas opiniões de determinados grupos sobre os temas tratados nas matérias jornalísticas ou outras formas de apresentação midiática (como novelas, programas de entretenimento, entre outros), como também determina quais temas serão trazidos à discussão e quais serão, portanto, omitidos, numa atividade de escolha conhecida como “agendamento":

\begin{abstract}
O agendamento estabelece uma relação causal entre as agendas noticiosa e pública, quer quanto aos temas mais relevantes, quer acerca da sua importância relativa. Tratase de um efeito não-intencional do processo de construção da actualidade informativa na configuração do ambiente político em que se forma a opinião pública. Ao excluírem, incluírem e hierarquizarem os acontecimentos diários, os jornalistas orientam a atenção do público para os assuntos destacados: a agenda dos media tornase a agenda pública. (BORGES, 2010, p. 137-144)
\end{abstract}

Por esta razão, observa-se o papel de grande importância ocupado pela mídia na formação informal da vontade que influenciará o processo político. Nas escolhas, por exemplo, dos temas tratados, de sua forma de apresentação e das opiniões apresentadas observa-se o 
posicionamento pessoal dos responsáveis pelo agendamento em relação aos problemas constatados no mundo da vida e à própria problematização dos temas levados à atenção do grande público.

Seja com maior ou menor grau de isenção, nas matérias jornalísticas e programação midiática em geral são apresentados, assim, posicionamentos ideológicos. E a ideologia, vista como um "corpo de crenças que assegura a relação de um grupo com um mundo social” (CORREIA, 2010, p. 10) pode exercer tanto funções de legitimação, de integração e preservação da identidade de um determinado grupo, quanto uma função de distorção e manipulação (CORREIA, 2010).

Desta feita, pode ocorrer, por exemplo, o uso abusivo do poder de grupos midiáticos em relação a outros grupos em razão desse controle ideológico:

Na reprodução discursiva da ideologia, os media ganham uma posição fundamental pela sua relação com a problemática da influência, isto é no que diz respeito à dimensão cognitiva do controle da mente exercida de forma indirecta e persuasiva pelo discurso dos grupos mais poderosos. (CORREIA, 2010, p. 14, destaque nosso)

Os donos dos grupos midiáticos fazem parte dos grupos mais poderosos e procuram exercer o controle dos grupos menos poderosos a partir das quatro seguintes circunstâncias descritas pelo autor:

a) A posição de especial credibilidade em que se encontram os grupos que promovem as crenças e as opiniões dominantes: académicos, peritos, profissionais, media de referência. O acesso a estes produtores privilegiados do discurso credível é estratificado. A teoria dos definidores primários (Hall, 1993) confirma esta hipótese e demonstra como os media, devido à sua necessidade de fontes credíveis, ficam dependentes da ideologia veiculada pelas instituições mais poderosas, olhadas como possuidoras de maior credibilidade;

b) Os grupos mais desfavorecidos encontram-se muitas vezes em condições nas quais lhes é impossível furtarem-se à exposição ao discurso veiculado pelos grupos mais poderosos;

c) Verifica-se a ausência de discursos ou media a partir dos quais derivem versões alternativas àquelas veiculadas pelo discurso produzido pelos grupos mais poderosos;

d) Constata-se a desigualdade na distribuição de conhecimentos que permitam refutar os elementos conceptuais constantes do discurso hegemónico. (CORREIA, 2010, p. 14)

Ademais, a possibilidade de uso dos meios de comunicação para distorção e manipulação representaria grande risco para a formação não viciada da vontade, tendo como base os ensinamentos de Habermas: 
Em Habermas (1987), a ideologia, na sua função de distorção, diz respeito a elementos pseudo - comunicacionais que pela sua natureza meramente estratégica colocam obstáculos à realização de um consenso racional, livre de toda a coerção, elemento regulador que norteia assintoticamente a prática social e política. Enquanto a acção instrumental se identifica com uma razão orientada para o sucesso, do tipo instrumental ou estratégico, a acção comunicativa, fundada na linguagem, busca um ideal de comunicação entre os actores que implica o reconhecimento mútuo. (CORREIA, 2010, p. 15)

Neste contexto a ideologia aparece como distorção instrumental que coloca obstáculos à concretização dos ideais normativos do discurso. Habermas entende o núcleo do paradigma procedimental do direito nos seguintes termos: “a 'combinação universal e a mediação recíproca entre a soberania do povo institucionalizada juridicamente e a nãoinstitucionalizada', são a chave para se entender a gênese democrática do direito” (2010, vol. II, p. 186). Habermas alerta contra a possibilidade da absorção da esfera pública pelo poder. E chama a atenção para o cultivo de esferas públicas autônomas, a participação maior das pessoas, a domesticação do poder da mídia e as tentativas de controle constitucional maior do seu poder, pois ela pode inviabilizar a democracia, inviabilizando a formação livre da opinião e da vontade. Neste contexto Correia apresenta o seguinte comentário.

\begin{abstract}
A ideologia, como distorção, identifica-se com a uma estratégia de manipulação da opinião pública que impede o seu desenvolvimento de acordo com as regras da argumentação racional e com os princípios de acessibilidade universal ao debate das questões de interesse colectivo. Sob o ponto de vista da comunicação política, identifica-se com o conjunto de procedimentos identificados como publicidade manipulativa, centrada na medição de atitudes individuais e na adopção de instrumentos operatórios destinados à transmissão passiva de mensagens. Reflecte a consideração da opinião pública com uma instância receptiva em relação à publicidade manipulativamente difundida de pessoas e instituições, bens de consumo e programas (Habermas, 1987 - b: 187). Traduz-se na ausência de um debate onde se proceda ao exame crítico de várias opções contraditórias, como sucede na publicidade crítica. Esta concepção de ideologia traduz a presença da racionalidade estratégica no plano da comunicação pública, expressa em dispositivos como sejam o spinning, lobbing, manipulação mediática. (CORREIA, 2010, p. 15-16)
\end{abstract}

Portanto, a mídia pode servir como um hábil instrumento de apresentação de ideias, debates e discussões para a busca do consenso em uma situação ideal de comunicação, inclusive com a apresentação de ideologias diversas para que os diferentes grupos existentes em uma determinada sociedade encontrem um espaço de fala e manifestação e para permitir, também, mudanças no pensamento tradicional. Todavia, sua participação na formação informal da vontade, se inadequada, prestando-se a funções de distorção da realidade e manipulação da 
massa, pode causar graves prejuízos ao processo democrático, mantendo-se no poder apenas grupos ideológicos com maior poder de influência midiática e excluindo-se os demais grupos, que representem diferentes parcelas da população.

\subsection{O controle da mídia no Brasil: pesquisa sobre a transparência dos proprietários da mídia}

Recentemente, em outubro de 2017, foi publicado o resultado de uma pesquisa realizada pela organização Repórteres Sem Fronteiras, em parceria com o coletivo Intervozes, intitulada “Os donos da Mídia”.

Foi apresentado relatório da pesquisa, realizada no Brasil entres os meses de Julho a Outubro de 2017, em que constavam dados sobre os 40 (quarenta) maiores grupos de mídia do país.

A “Repórteres sem Fronteiras” (“Reporters Without Borders”), principal responsável pelo estudo, constitui-se como uma organização internacional independente, fundada em 1985 e sediada em Paris, França. Mantém um status consultivo com as Nações Unidas, a UNESCO e o Conselho da Europa. "Suas filiais no exterior, seus escritórios em dez cidades, incluindo Bruxelas, Washington, DC, Berlim, Tunes, Rio, Estocolmo e sua rede de correspondentes em 130 países dão-lhe uma forte capacidade de mobilização e interpelação” (RSF, on-line, tradução nossa).

Conforme informações do sítio eletrônico da organização, ela se orienta considerando a liberdade de expressão e de informação como principal liberdade. Desenvolve seus próprios métodos e indicadores com o fim de tornar mais eficiente seu trabalho de levantamento de dados e transmissão da informação. É reconhecida internacionalmente e já recebeu vários prêmios pelo seu trabalho de promover a liberdade de imprensa.

O Coletivo Intervozes - Coletivo Brasil de Comunicação Social, que colaborou com a pesquisa, é uma organização brasileira que, como declara em sua página eletrônica, “trabalha pela efetivação do direito humano à comunicação no Brasil” e parte do pressuposto de que “o direito à comunicação é indissociável do pleno exercício da cidadania e da democracia: uma sociedade só pode ser chamada de democrática quando as diversas vozes, opiniões, culturas e raças que a compõem têm espaço para se manifestar” (INTERVOZES, on-line).

A pesquisa “Os donos da mídia” (no original “The Media Ownership Monitor MOM”) faz parte de uma pesquisa mais ampla, já realizada em diversos países, tais como 
Colômbia, Turquia, Peru, Ucrânia e Filipinas, com o objetivo de estabelecer um mapa das principais redes de comunicação midiática em cada país, a fim de avaliar os riscos decorrentes de uma mídia imparcial e plural.

O pluralismo na mídia é um aspecto chave de sociedades democráticas livres,
independentes e diversas, vez que reflete divergências de pontos de vista e permite a
crítica às pessoas que detém o poder. Riscos à diversidade de idéias são causados pela
concentração do mercado midiático, quando somente poucos jogadores dominantes
influenciam a opinião pública e criam barreiras de entrada para outros jogadores e
outras perspectivas (concentração dos donos da mídia). O maior obstáculo a combater
é a falta de transparência acerca dos proprietários da mídia: como as pessoas podem
avaliar a confiabilidade da informação se elas não sabem quem as está provendo?
Como jornalistas podem trabalhar adequadamente se eles não sabem quem controla a
companhia para quem eles trabalham? E como as autoridades que controlam a mídia
podem lidar com a excessiva concentração da mídia em poucos grupos se eles não
sabem quem está por trás da engrenagem? (MOM, on-line, tradução nossa)

Observa-se, pois, que a preocupação acerca da existência de uma mídia imparcial e plural é objetivada pela busca do estabelecimento de um processo verdadeiramente democrático em cada sociedade. Diante disso, estabeleceram-se os objetivos principais da pesquisa:

MOM pretende criar transparência e responder a questão: quem acaba por controlar o que é transmitido na mídia? Pretende fazê-lo com o objetivo de trazer consciência ao público e de criar uma base de dados para que se possa responsabilizar os jogadores políticos e econômicos envolvidos. (MOM, on-line, tradução nossa)

Para a realização da pesquisa no Brasil foram analisados 50 (cinquenta) veículos em 04 (quatro) segmentos (TV, rádio, mídia impressa e online) e o resultado apresentado indica, segundo os organizadores da pesquisa, “alerta vermelho”, tendo em vista, entre outros fatores retratados, a falta de transparência acerca do controle midiático no país. "O sistema de mídia mostra alta concentração de audiência e de propriedade, alta concentração geográfica, falta de transparência, além de interferências econômicas, políticas e religiosas” (MOM BRAZIL, online).

Conforme relatos da organização acerca da transparência dos donos da mídia no Brasil:

As companhias de mídia pesquisadas pela MOM Brasil não publicam ativamente os dados sobre seus sócios e proprietários e nenhuma delas respondeu aos requerimentos da equipe da MOM. Alguns alegaram "estratégia” ou razões de competição no mercado como motivos para não fornecer as informações. Meios alternativos de obter esses dados são tediosos e limitados. Não há meio legal de compelir as empresas a tornarem transparentes tais informações sobre a estrutura das sociedades, sócios, equipe comercial, não há política eficiente para acessar essas informações e validálas. O sistema vigente que permite a obtenção de dados sobre os proprietários das licenças de rádio e TV não garante que tais dados estejam atualizados nem que sejam 
detalhados o suficiente para que se possa identificar os donos individualmente. As companhias, em geral, não demonstram qualquer iniciativa para adquirir maior transparência, e as estruturas complexas das organizações com as múltiplas possibilidades legais não facilitam isso. (MOM, on-line, tradução nossa)

Do exposto fica clara a importância do espaço informal de formação da opinião para a democracia. Bem como a importância da mídia e de seu controle, que pode contribuir com o aprimoramento da democracia ou trazer o fortalecimento das ideologias dominantes e distanciar a comunicação de seus pressupostos normativos, levando a irracionalidades e patologias na formação da opinião e vontade no processo democrático, o qual depende visceralmente da conexão da opinião informal com a institucionalização do direito para sua legitimação.

\section{A sinceridade na ética discursiva e a transparência no controle midiático no Brasil}

Considerando os dados apresentados pela pesquisa “Os donos da mídia” e os resultados acerca da transparência no controle da mídia no Brasil, analisa-se, sob a ótica da Teoria do Discurso de Habermas, o preenchimento do requisito da sinceridade quanto à falta de transparência acerca dos proprietários individuais da mídia no país, principalmente de rádio e televisão.

A sinceridade, em tese, se refere a um ponto subjetivo do discurso, visto que está diretamente ligada às intenções do sujeito falante, que podem ou não ser manifestadas em sua fala. Pressupõe-se que "a intenção manifesta do falante é visada do modo como é proferida” (PROCÓPIO, 2012, on-line).

O que se espera no momento da ação comunicativa é que todos os falantes atuem com
sinceridade, acreditem naquilo que estão expondo e que possam argumentar sobre as
suas falas. Com a prática da comunicação, o indivíduo reflexivamente se prepara para
novas argumentações, seja revendo seus conceitos e posicionamentos ou mesmo
mantendo as suas conviçções com mais argumentos no decorrer do processo
comunicativo. Nenhuma autoridade detém o poder ou a possibilidade de alterar o
pensamento interno individual, mas todos os participantes do discurso podem
interferir na condução e na busca de um consenso alcançado discursivamente.
(MARQUES, 2015, on-line).

Na pesquisa realizada, observou-se a falta de dados públicos acerca de quem são os proprietários individuais dos principais meios de comunicação, principalmente em rádio e TV. Conforme relatos da instituição organizadora, não havia transparência e fácil acesso aos dados buscados e, ao serem questionados diretamente, nenhum dos grupos midiáticos forneceu os 
dados solicitados, alguns apresentando a justificativa de que a ausência de resposta se dava por motivos estratégicos e de competição.

Em tais declarações os proprietários midiáticos expressaram interesse no desconhecimento, pelo ouvinte, das características de identificação do falante, não havendo esclarecimento de motivos claros que levaram os proprietários a essa tomada de posição, visto que a justificativa genérica por “motivos estratégicos e de competição” não deixa transparecer se tais motivos seriam apenas de natureza econômica, por exemplo, ou também políticas e / ou ideológicas.

Não foi possível, portanto, esclarecer se isso também se dá por um desinteresse dos proprietários midiáticos no conhecimento, pelo público, de suas verdadeiras intenções no discurso proferido pela mídia em grande escala, o que permite concluir pelo não atendimento ao pressuposto da sinceridade na ação discursiva.

Ainda que não seja possível auferir, com precisão, as intenções reais dos proprietários dos grupos midiáticos quando da organização da sua programação de temas e discursos e, dessa forma, não seja possível constatar se as intenções subjetivas estão de acordo com os discursos proferidos, ainda assim não se observa o atendimento ao requisito da sinceridade pela Teoria do Discurso de Habermas.

Isso porque, de acordo com Habermas, a ética do discurso pretende trazer certa racionalidade à ética, possibilitando uma argumentação e análise racional da fala para que esta possa ser avaliada e que possa ser confirmada a validade do processo comunicativo:

3. quando uma pessoa pratica um ato de fala expressivo (emotivo), esse ato tem uma pretensão de sinceridade, mas essa sinceridade não pode ser demonstrada argumentativamente, podendo ser apreendida apenas pela análise do efetivo comportamento do falante.

Dessa forma, tanto a verdade das proposições assertóricas quanto a validade das proposições normativas (deônticas) deve poder ser resgatada argumentativamente, ou seja, deve haver bons argumentos, que as fundamentem (COSTA, 2012, on-line).

Assim, a própria ausência das informações de forma pública e clara e a negativa no seu fornecimento já permitiriam o surgimento de dúvidas acerca da sinceridade dos interlocutores, vez que “a pretensão de sinceridade não é resolvida discursivamente, pois se minha sinceridade fosse dúbia, não haveria como eu provar estar sendo sincero com argumentos. Visto que a única forma de denotar sinceridade é através de meus próprios atos” (NOGUEIRA, 2006, on-line). 
Ademais, Habermas traz a "ideia de que a dominação não se exerce pela linguagem, já que todos temos o direito de dizer não, assim só há poder em operações extralinguísticas” (RIBEIRO, TEMER e TUZZO, 2013, p. 190).

Essa dominação poderia ser exercida, por exemplo, com a ausência de comunicação clara acerca dos reais interesses dos participantes, visto que a linguagem pode ser utilizada de formas diversas e para finalidades diversas.

Pascal Ide, em seu livro “A arte de Pensar” (2000), discorre sobre técnicas de argumentação lógica utilizadas para a comunicação e, também, para o convencimento do ouvinte, tais como o raciocínio pelo exemplo, o raciocínio pelo lugar comum e o uso de figuras de autoridade. Tratam-se de técnicas de argumentação que auxiliam na compreensão das ideias do falante.

Utilizando-se desses conceitos, verifica-se que com a simples falta de transparência sobre os proprietários das mídias no Brasil, principalmente as que exercem maior influência sobre a massa, a dominação também pode dar-se, por exemplo, pela indução a determinadas linhas de pensamento tidas como “verdade absoluta” ou “conhecimento notório”.

Para isso, bastaria o uso de técnicas próprias de retórica, tais como o argumento pelo exemplo e por figuras de autoridade, utilizando-se do pensamento e imagem de personalidades públicas com grande influência sobre determinados grupos, ou, ainda, com argumentos de "lugar comum”, que pretendem trazer verdades ideológicas como verdades universais.

Ressalte-se que não representa qualquer problema à comunicação a defesa de ideologias específicas, visto que “na esfera pública luta-se por influência” (HABERMAS, 2010, vol. II), mas desde que sejam claros os posicionamentos ideológicos tomados e suas razões, a fim de viabilizar aos demais participantes do debate meios verdadeiros de questionar e escolher racionalmente.

Habermas apresenta quatro modelos do agir: o teleológico “é ampliado a agir estratégico quando pelo menos um ator que atua orientado a determinados fins revela-se capaz de integrar ao cálculo de êxito a expectativa de decisões” (2012b, p. 163-164), o regulado por normas "o conceito central cumprimento de norma significa a satisfação de uma expectativa de comportamento generalizada” (2012b, p. 164); o dramatúrgico “o conceito central de autorrepresentação não significa um comportamento expressivo espontâneo, mas a estilização da expressão de vivências próprias, endereçada a espectadores” (2012b, p. 165); e, por fim, o Agir comunicativo: 
Somente o modelo comunicativo de ação pressupõe a linguagem como um médium de entendimento não abreviado, em que falantes e ouvintes a partir do horizonte de seu mundo da vida previamente interpretado, referem-se simultaneamente a algo no mundo objetivo, social e subjetivo a fim de negociar definições em comum para as situações. (2012b, p.183-184)

Habermas explica que "as qualidades do agir dramatúrgico são de certo modo parasitárias; ficam sujeitas à estrutura de um agir que se orienta segundo fins determinados” (2012b, p. 175). Ele continua mais adiante:

É possível que o representador só esteja interessado em influenciar as convicções de seu público e com sua situação seja mesmo indiferente. Se o representador não está convencido de seu próprio papel e não está seriamente interessado em seu público, chamemo-lo de cínico, ao passo que reservamos o termo 'sincero' para representadores que creem na impressão que sua própria apresentação ocasiona. Temse assim a criação intencional de impressões falsas.

A falta de transparência nos meios de comunicação de massa coloca-os na linha de uma ação dramatúrgica estratégica que visa à manipulação da consciência das massas em detrimento de sua contribuição com o agir comunicativo e a livre formação da opinião e da vontade.

Não se trata de excesso de idealização do processo de comunicação, mas de respeito a regras objetivas que o tornem minimamente confiável à interação:

\begin{abstract}
Apesar de tudo, importa restringir este raciocínio. Contra as sucessivas críticas que fazem atribuir a Habermas a adopção de um ponto de vista idealista e carente de concretização, Ferry adopta uma curiosa defesa das idealizações necessárias, retomando o argumento segundo o qual sem assumir tais idealizações seria impossível a busca de um entendimento com alguém a propósito do que quer que fosse. Nesta medida, desenvolve a ideia engenhosa segundo a qual se é verdade que não existe comunicação ideal e transparente não é menos verdade que é possível existir um ideal de comunicação. Sem ideal de comunicação não existiria crítica e qualquer pretensão normativo morreria às mãos de um “excesso de realidade” (cfr. Ferry, 2002:30). (CORREIA, 2005, p. 45-46)
\end{abstract}

Busca-se, então, formas objetivas para se constatar como é formado o consenso nos debates informais e, para isso, é necessário “pressupor a exclusão de toda a força que não seja aquela que resulte do melhor argumento, neutralizando-se qualquer motivo que não seja o da busca cooperativa da verdade e da adequação normativa” (CORREIA, 2005, p. 42).

A falta de transparência, portanto, acerca da identidade e, por consequência, dos interesses pessoais, sejam econômicos, políticos, religiosos e/ou ideológicos, dos proprietários 
das grandes mídias, responsáveis pelo agendamento, objetivamente exclui da comunicação midiática o atendimento ao requisito da sinceridade no discurso.

\section{CONCLUSÃO}

Questionou-se no início deste artigo: Como a transparência da informação dos donos e efetivos detentores do poder decisório nos meios de comunicação de massa no Brasil compromete sua autenticidade, e condições necessárias da ética do discurso, pondo em risco a livre formação da opinião e da vontade?

Verificou-se que entre as exigências da Ética do discurso está o quesito da sinceridade, que também manifesta-se como autenticidade. Porém, intenções podem ser dissimuladas em ações cínicas através da ação dramatúrgica, pondo-se em oposição a autêntica ação comunicativa.

Observa-se, pelos dados analisados, que não há o atendimento ao requisito de sinceridade, sob a ética discursiva de Habermas, pela comunicação midiática no país, representada nesse estudo pelos maiores grupos controladores da mídia no Brasil, especialmente de rádio e televisão, tendo em vista a falta de transparência acerca da identificação dos proprietários individuais da mídia, seus interesses e ideologias.

Com o não atendimento da regra de sinceridade e, portanto, a ausência de confirmação e de possibilidades objetivas de verificação das intenções do interlocutor, não se pode falar da ocorrência de uma comunicação válida e, por conseguinte, de uma real arena de discussão, ampla e livre, para o debate de ideias e formação informal da opinião, o que prejudica, em demasia, a realização de um processo verdadeiramente democrático no Brasil. A formação da opinião e da vontade fica comprometida em sua liberdade, quando privada dos meios necessários para se defender do cinismo, dos interesses e das ideologias dos poderosos donos da mídia e meios de comunicação de massa.

O comprometimento da democracia é inequívoco, bem como a exigência da identificação dos donos, a transparência das intenções editoriais e a clara distinção entre opinião e informação. Sem as quais não pode haver confiabilidade e interação comunicativa, mas apenas competição ideológica e estratégica pelo adestramento das massas. A multiplicação dos meios e o controle da excessiva concentração dos meios é por tanto condição necessária para a manutenção e aprimoramento da democracia através da formação de consensos autênticos e legítimos.

Revista de Teorias da Democracia e Direitos Políticos | e-ISSN: 2525-9660 | Salvador | v. 4 | n. 1 | p. 1 - 17 | Jan/Jul. 2018 


\section{REFERÊNCIAS}

BORGES, Susana. Agendamento. In: CORREIA, João Carlos; FERREIRA, Gil Baptista; ESPÍRITO SANTO, Paula do (Coord.). Conceitos de Comunicação Política. Série: Estudos em Comunicação. Covilhã: Editora Universidade da Beira Interior, 2010.

CHOMSKY, Noam. Mídia: propaganda política e manipulação. Trad. Fernando Santos. São Paulo: Martins Fontes, 2014.

COSTA, Alexandre Araújo. A ética do discurso em Habermas. Disponível em: http://www.arcos.org.br/artigos/a-etica-do-discurso-em-habermas. Acesso em 15/11/2017.

CORREIA, João Carlos. Ideologia, Crítica e Deliberação. In: CORREIA, João Carlos; FERREIRA, Gil Baptista; ESPÍRITO SANTO, Paula do (Coord.). Conceitos de Comunicação Política. Série: Estudos em Comunicação. Covilhã (Portugal): Editora Universidade da Beira Interior, 2010.

. Jornalismo e Espaço Público. Série: Estudos em Comunicação. Covilhã (Portugal): Editora Universidade da Beira Interior, 1998.

. Sociedade e Comunicação: estudos sobre jornalismo e identidade. Série: Estudos em Comunicação. Covilhã (Portugal): Editora Universidade da Beira Interior, 2005.

Teoria e Crítica do Discurso Noticioso: notas sobre jornalismo e representações sociais. Série: Estudos em Comunicação. Covilhã (Portugal): Editora Universidade da Beira Interior, 2009.

HABERMAS, Jürgen, Agir Comunicativo e razão destranscendentalizada. Tradução Lucia Aragão. Rio de Janeiro: Tempo Brasileiro, 2012.

Direito e Democracia: entre facticidade e validade. Vol. I. Trad. Flábio Beno Siebeneichler. Rio de Janeiro: Tempo Brasileiro, 2010.

Direito e Democracia: entre facticidade e validade. Vol. II. Trad. Flábio Beno Siebeneichler. Rio de Janeiro: Tempo Brasileiro, 2010.

. Entre Naturalismo e Religião: Estudos filosóficos. Trad. Flávio Beno Siebeneichler. Rio de Janeiro: Tempo Brasileiro 2007.

. Mudança estrutural da esfera pública: investigações quanto a uma categoria da sociedade burguesa. Rio de Janeiro: Tempo Brasileiro, 2003.

Teoria do agir comunicativo: racionalidade do agir comunicativo. Racionalidade da ação e racionalização social. Vol. I. Trad. Paulo Astor Soethe. São Paulo: Martins Fontes, 2012 a.

HOBBES, Thomas de M. Leviatã ou matéria, forma e poder de um Estado eclesiástico e civil. Trad. João Paulo Monteiro e Maria Beatriz Nizza da Silva. São Paulo: Nova cultural, 1988.

Revista de Teorias da Democracia e Direitos Políticos | e-ISSN: 2525-9660 | Salvador | v. 4 | n. 1 | p. 1 - 17 | Jan/Jul. 2018 
IDE, Pascal. A arte de pensar. Trad. Paulo Neves. 2. Ed, São Paulo: Martins Fontes, 2000.

INTERVOZES. Coletivo Brasil de Comunicação Social. Sítio eletrônico: http://intervozes.org.br/. Acesso em 15/11/2017.

MARQUES, João Henrique Wilkon. Jürgen Habermas e Robert Alexy: diálogo entre o consenso de Habermas e a interpretação de Alexy. Disponível em: http://repositorio.uniceub.br/bitstream/235/8516/1/21246209.pdf. Acesso em 15/11/2017.

MOM. Media Ownership Monitor. Sítio eletrônico: http://www.mom-rsf.org/. Acesso em 15/11/2017.

MOM, Brasil. Sítio eletrônico: http://brazil.mom-rsf.org/br/. Acesso em 15/11/2017.

NOGUEIRA, Clayton Ritnel. A Teoria Discursiva de Jürgen Habermas. Disponível em: https://www.direitonet.com.br/artigos/exibir/2715/A-teoria-discursiva-de-Jurgen-Habermas.

Acesso em 15/11/2017.

PROCÓPIO, Marcos Luís. Consciência Moral e Agir Comunicativo. Revista do Centro Interdisciplinar de Desenvolvimento e Gestão Social. V. 3, n. 2, jul./dez. 2012. Disponível em: http://www.periodicos.adm.ufba.br/index.php/cgs/article/download/300/240. Acesso em 15/11/2017.

RIBEIRO, TEMER e TUZZO. Cidadania e democracia deliberativa na era digital - para além de Habermas. Revista Comunicação \& Informação. V. 16, n. 1, p. 186-201, jan./jun. 2013. Disponível em: https://www.revistas.ufg.br/ci/article/download/26706/15340. Acesso em 23/11/2017.

RSF, Reporters Without Borders. Sítio eletrônico: https://rsf.org/fr/presentation-0. Acesso em 15/11/2017. 